\title{
Mines et métallurgies préhistorique du Midi de la France
}

Paul Ambert

\section{OpenEdition Journals}

Édition électronique

URL : http://journals.openedition.org/adlfi/11612

ISSN : 2114-0502

Éditeur

Ministère de la culture

Référence électronique

Paul Ambert, " Mines et métallurgies préhistorique du Midi de la France », ADLFI. Archéologie de la France - Informations [En ligne], Languedoc-Roussillon, mis en ligne le 01 mars 2004, consulté le 20 avril 2019. URL : http://journals.openedition.org/adlfi/11612

Ce document a été généré automatiquement le 20 avril 2019

(c) Ministère de la Culture et de la Communication, CNRS 


\title{
Mines et métallurgies préhistorique du Midi de la France
}

\author{
Paul Ambert
}

\author{
Identifiant de l'opération archéologique : \\ Date de l'opération : 1996 - 1999 (PC) \\ Inventeur(s) : Ambert Paul (CNRS)
}

1 Depuis 1996, plus de cent quatre-vingts minerais et objets métalliques chalcolithiques ont été analysés par spectrographie, alors que désormais nous utilisons les services de plusieurs laboratoires pour obtenir des analyses chimiques globales et des études au microscope électronique à balayage. Dans ce cadre Thorsten Schifer (université de Freibourg, Brisgau) a proposé une synthèse renouvelée du potentiel minéral de Cabrières (Schifer, Thorsten. 2000.).

2 En sus de l'accentuation des recherches dans la région de Cabrières, nos travaux dans les mines ont porté principalement sur le pôle du Gard occidental (Durfort, Villemagne, Aigoual). Elles ont également concerné les secteurs du Lodévois, Bédarieux, haute vallée de l'Orb, intermédiaires entre les pôles de forte métallurgie chalcolithique du bas Languedoc et des Causses.

3 Depuis fin 1996, suivi du traitement des mines orphelines de Cabrières par la DRIRE Languedoc-Roussillon, en relation avec la DRAC Languedoc-Roussillon.

4 Au-delà des nombreuses réunions, courriers, coups de téléphone et rapports que l'opération de la DRIRE a entraîné, le suivi a nécessité deux grosses opérations :

5 Une autre opération de pompage, avec le concours de la COGEMA dans la mine de Pioch Farrus IV a permis le désennoyage d'un important réseau minier antique. Les principaux résultats ont été publiés dans les actes du colloque de Cabrières 1997 (Ambert, Paul (dir.). 1997.). Rappelons ici que la base d'une partie du réseau antique a été atteinte à la côte $-27 \mathrm{~m}$ par rapport à l'entrée de la mine (Fig. $\mathrm{n}^{\circ} 1$ : Mine de Pioch-Farrus IV (Cabrières, Hérault). Plan de la cavité réalisé dans le cadre du PCR « Mines et métallurgies 
préhistoriques du Midi de la France »). Il y a été mis au jour plusieurs aménagements complémentaires de ceux découverts en 1984 (Bailly-Maître, Marie-Christine ; Houlès, Noël ; Landes, Christian. 1984.).

[(Ambert, Paul (dir.). 1992.) ; (Ambert, Paul (dir.). 1996.) ; (Ambert, Paul. 1995.) ; (Ambert, Paul. 1996.) ; (Ambert, Paul. 1998.) ; (Ambert, Paul. 1999.) ; (Ambert, Paul. 1999.) ; (Ambert, Paul ; Carozza, Laurent. 1998.) ; (Ambert, Paul ; Carozza, Laurent ; Lechelon, Bernard ; Houles, Michel. 1998.) ; (Esperou, Jean-Luc ; Ambert, Paul ; Bourhis, Jean-Roger ; Roques, Pierre ; Gilot, Étienne ; Chabal, Lucie. 1994.) et (Happ, Jacques ;, Ambert, Paul ; Bourhis, Jean-Roger ; Briard, Jacques. 1994.)].

\section{BIBLIOGRAPHIE}

Schifer, Thorsten. 2000 : «Le Minerai de cuivre de Cabrières (Hérault, France) », Archéologie en Languedoc, 24, p. 173-182.

Ambert, Paul (dir.). 1997 : « Mines et métallurgies de la Préhistoire au Moyen Âge dans le sud de la France (domaines méditerranéen et alpin), état de la question, perspectives de recherche, actes $\mathrm{du}$ colloque Mines et métallurgie de la Préhistoire au Moyen Âge en Languedoc-Roussillon et 
régions périphériques, colloque Cabrières 97 », Ambert Paul Ed., Lattes, Fédération archéologique de l'Hérault, Archéologie en Languedoc, 21, 248 p.

Bailly-Maître, Marie-ChristineHoulès, NoëlLandes, Christian. 1984 : « Le site minier antique de Pioch-Farrus commune de Chabrieres, Herault : recherches preliminaires », Revue archéologique de Narbonnaise, 17, p. 327-337, 12 fig.

Ambert, Paul (dir.). 1992 : « Le Chalcolithique en Languedoc, ses relations extra-régionales, colloque international, hommage au docteur Jean Arnal, Saint-Mathieu-de-Tréviers, Hérault, 20-22 septembre 1990, Lattes », Fédération archéologique de l'Hérault, Archéologie en Languedoc, $15,352 \mathrm{p}$.

Ambert, Paul (dir.). 1996 : «Cabrières-Hérault et le contexte régional du développement de la première métallurgie du cuivre en France méridionale (III ${ }^{\mathrm{e}}$ millénaire av. J.C.) », Archéologie en Languedoc, 20, 1, p. 1-70.

Ambert, Paul . 1995 : «Les mines préhistoriques de Cabrières (Hérault) : quinze ans de recherches, état de la question ", Bulletin de la Société préhistorique française, 92, 4, p. 499-508.

Ambert, Paul . 1996 : Cabrières (France) : III ${ }^{e}$ Millenium B.C, mines and copper metallurgy, XIII ${ }^{e}$ congrès international UISPP de Forli, colloque 10, p. 41-50.

Ambert, Paul . 1998 : « Métallurgie préhistorique, métallurgie expérimentale : Les fours, état de la question, perspectives de recherches, colloque Bourg-en-Bresse, Beaune, 1997 ", Monographies Instrumentum, 5, p. 1-17, 9 fig., 1 tabl.

Ambert, Paul . 1999 : Grandeurs et décadences des exploitations de cuivre de Cabrières (Hérault), entre Néolithique et Moyen-Age, Hommage à Claude Domergue 2, Toulouse, Pallas, 50, p. 391-404.

Ambert, Paul. 1999 : « Les minerais de cuivre et les objets métalliques en cuivre à antimoineargent du sud de la France, Preuves d'une exploitation minière et métallurgique du début du III millénaire BC, colloque international d'Heildelberg-Bochum, 26-28 avril 1995 », Der Aschnitt, B. 9, p. $193-210$.

Ambert, PaulCarozza, Laurent. 1998 : «Origine(s) et développement de la première métallurgie en France, état de la question, Hommage à Christian Strahm », Rahden, Westfalia, Müller, Johannes Wolf, Claus Ed. Internationale Archäologie, Studia honoraria, 3, p. 149-174.

Ambert, PaulCarozza, LaurentLechelon, BernardHoules, Michel. 1998 : « De la mine au métal au sud du Massif central au chalcolithique, Données nouvelles : régions de Cabrières, Fayet, Villefranche-de-Rouergue (régions de Cabrières, Fayet, Villefranche de Rouergue) », L'Atelier du bronzier en Europe du XX $X^{e}$ au VIII ${ }^{e}$ siècle avant notre ère, tome II, Du minerai au métal, du métal à l'objet, Paris, CTHS, p. 59-70.

Esperou, Jean-LucAmbert, PaulBourhis, Jean-RogerRoques, PierreGilot, ÉtienneChabal, Lucie . 1994 : « La Fosse chalcolithique Pioch-Farrus 448 (Cabrières, Hérault) : datation ${ }^{14} \mathrm{C}$ et documents métallurgiques », Bulletin du musée d'Anthropologie préhistorique de Monaco, 37, p. 53-62.

Happ, JacquesAmbert, PaulBourhis, Jean-RogerBriard, Jacques. 1994 : « Premiers essais de métallurgie expérimentale à l'archéodrome de Beaune à partir des minerais chalcolithiques de Cabrières (Hérault) », Bulletin de la Société préhistorique française, 91, 6, p. 429-434.

\section{ANNEXES}


Fig. $\mathrm{n}^{\circ} 1$ : Mine de Pioch-Farrus IV (Cabrières, Hérault). Plan de la cavité réalisé dans le cadre du $\mathrm{PCR}$ « Mines et métallurgies préhistoriques du Midi de la France »

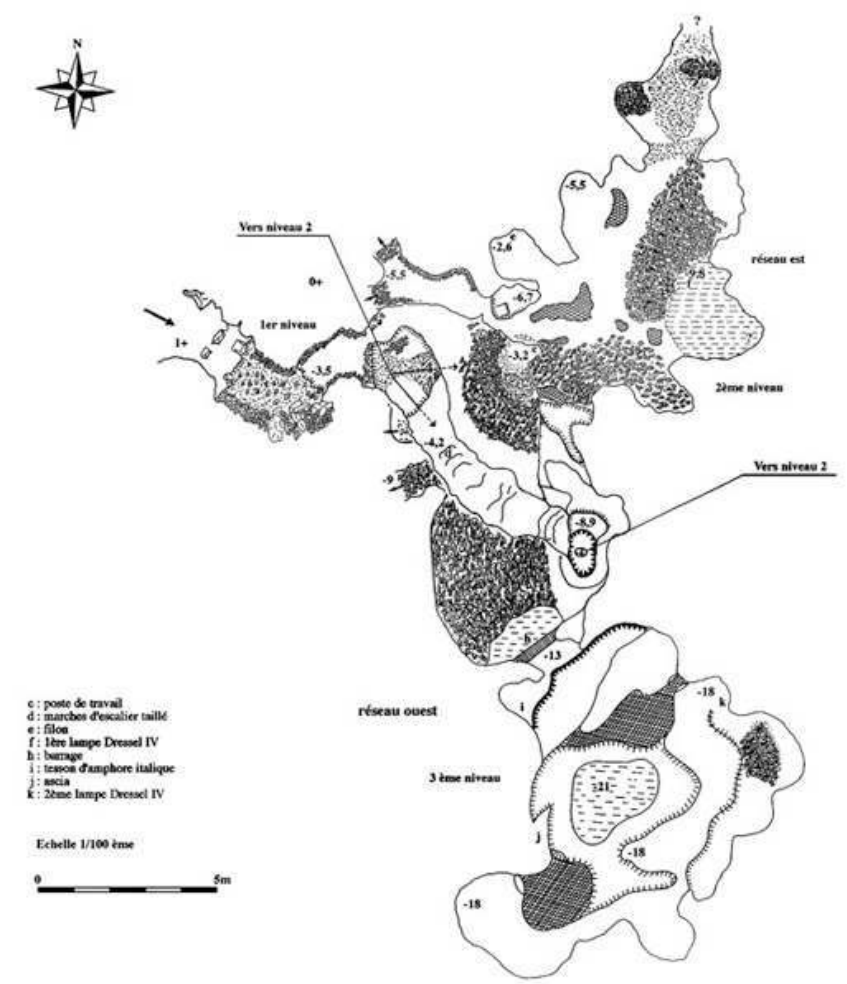

Auteur(s) : Salvaire, Michel. Crédits : ADLFI - Salvaire, Michel (2003)

INDEX

operation Projet collectif de recherche (PCR)

Index chronologique : Chalcolithique, Antiquité romaine

Index géographique : Languedoc-Roussillon, Hérault (34), Bédarieux, Cabrières, Lodève

\section{AUTEURS}

PAUL AMBERT

CNRS 